\title{
Vaginal rings for delivery of HIV microbicides
}

This article was published in the following Dove Press journal:

International Journal of Women's Health

19 November 2012

Number of times this article has been viewed

\section{R Karl Malcolm \\ Susan M Fetherston \\ Clare F McCoy \\ Peter Boyd \\ Ian Major}

School of Pharmacy, Queen's

University Belfast, Belfast, UK
Correspondence: R Karl Malcolm School of Pharmacy, Queen's University Belfast, Belfast BT9 7BL, UK

Tel +442890972319

Fax +44 2890247794

Email k.malcolm@qub.ac.uk
Abstract: Following the successful development of long-acting steroid-releasing vaginal ring devices for the treatment of menopausal symptoms and contraception, there is now considerable interest in applying similar devices to the controlled release of microbicides against HIV. In this review article, the vaginal ring concept is first considered within the wider context of the early advances in controlled-release technology, before describing the various types of ring device available today. The remainder of the article highlights the key developments in HIV microbicide-releasing vaginal rings, with a particular focus on the dapivirine ring that is presently in late-stage clinical testing.

Keywords: controlled release, sustained release, antiretroviral, dapivirine, SILCS diaphragm, silicone elastomer, thermoplastic

\section{Introduction to controlled drug release and vaginal rings}

The concept of controlled drug release from polymeric materials was first established in the 1960s by Judah Folkman when he discovered that exposure of anesthetic gases to the external surface of a silicone rubber arteriovenous shunt containing circulating rabbit blood caused the rabbits to fall asleep. ${ }^{1}$ Based on this ability of gaseous molecules to permeate silicone rubber, it was postulated that solid drugs incorporated into silicone rubber (or other elastomeric polymers) could be implanted in the body to provide rate-controlled drug-delivery systems. ${ }^{2,3}$ The first controlled-release drug-delivery systems to be commercialized were two devices: Alza’s Ocusert ${ }^{\mathbb{B}}$ (an ophthalmic insert releasing pilocarpine at a constant rate for the treatment of glaucoma) and Progestasert ${ }^{\circledR}$ (an intrauterine implant providing a constant rate of progesterone delivery). Both were reservoir-type devices fabricated from the thermoplastic polymer poly(ethylene-co-vinyl acetate) (PEVA). The first commercial silicone elastomer device for controlled release was the Population Council's subdermal contraceptive implant Norplant ${ }^{\circledR}$, first approved for use in Finland in 1983 and marketed in the USA in 1991. Consisting of six small $(2.4 \mathrm{~mm} \times 34 \mathrm{~mm})$ silicone elastomer cylinders, each filled internally with $36 \mathrm{mg}$ of levonorgestrel (a progestin used in many birth-control pills), Norplant ${ }^{\circledR}$ was a direct extension of Folkman's original concept and provided effective fertility control for five years. A second generation of Norplant ${ }^{\circledR}$-type devices is currently available, containing either one or two drug-loaded rods and fabricated from either silicone elastomer or PEVA.

In 1970, a US patent assigned to the UpJohn Company was published describing "an improved resilient annular device for intravaginal placement and retention . . . 
containing an effective amount of a medicament which is capable of passage through the drug-permeable polymeric material" (Figure 1A). ${ }^{4}$ This first description of the concept of a drug-releasing vaginal ring heralded an intense period of activity in ring development through the 1970s and 1980s, mainly focused around contraception and hormone replacement therapy and involving various ring designs. The World Health Organization (WHO) was at the forefront of this research with their program for the development of a silicone elastomer steroidal contraceptive ring to help contain the burgeoning population growth. The interested reader is directed to Hoffman's excellent overview on the origins and evolution of controlled-release drug-delivery systems. ${ }^{5}$

\section{Vaginal rings}

Vaginal rings are flexible, torus-shaped, silicone elastomer or thermoplastic devices that provide long-term, sustained or controlled delivery of pharmaceutical substances to the vagina for either local or systemic effect. Designed to be readily inserted and removed by the woman herself, they are
A



C

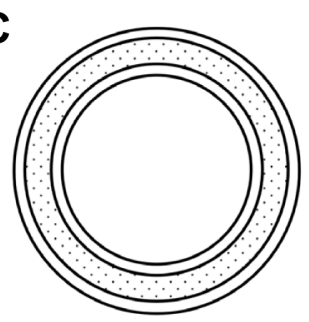

E

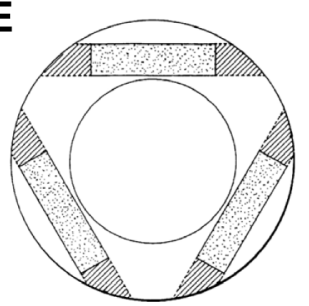

B

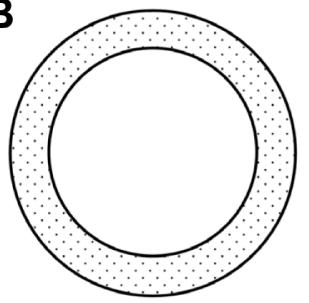

D

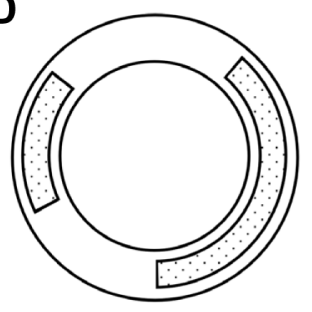

$\mathbf{F}$

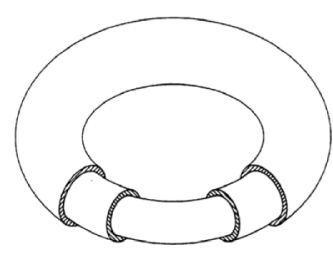

Figure I Representative vaginal ring designs. (A) Over-molded metal spring design first described in a 1970 patent. $^{4}$ (B) Matrix-type ring with solid micronized drug dispersed throughout the entire polymer. (C) Full length reservoir/core ring design, where the drug-loaded core is encapsulated by a nonmedicated, rate-controlling polymer membrane. (D) Multiple partial core ring design, where each core contains a different drug substance. (E) Insertable core ring design, where drug-loaded cores are inserted into a prefabricated ring body before sealing the ends. (F) Sandwich or shell ring design, where a drug-loaded layer is sandwiched between a nonmedicated polymeric central core and a nonmedicated outer rate-controlling polymer membrane. generally positioned in the upper third of the vagina adjacent to the cervix. Although the exact location of ring placement is generally not critical for clinical efficacy, it may have implications for comfort in some women.

The simplest vaginal ring design contains solid drug particles (usually in a micronized form) dispersed throughout the entire polymeric matrix. The drug-release yield from these so-called "homogeneous" or "matrix" rings (Figure 1B) is governed by a permeation mechanism for which the release rate is dependent upon (1) the drug's solubility in the polymer, (2) the ability of the solvated drug to diffuse through the polymer, (3) the drug-loading within the device, and (4) the ring surface area. The drug-permeation process involves dissolution of the solid drug in the polymer, followed by diffusion of the solubilized molecules through the elastomeric polymer network. Drug near the surface of a matrix ring is released first, creating a drug-depleted layer through which solubilized molecules within the ring body must first diffuse in order to be effectively released. As time progresses the surface area of this inward-moving depletion boundary decreases, causing an increase in the thickness of the depletion layer, resulting in decreased drug-release rates over time.

The "sandwich" and "core" vaginal ring designs (also known as "shell" and "reservoir," respectively) were developed to provide constant daily release rates throughout the period of use, conforming to "zero order" release kinetics. The sandwich design (Figure 1F) consists of a narrow drugloaded polymer layer positioned between a nonmedicated inner central core and a nonmedicated outer membrane. The position of the drug core close to the surface ensures efficient delivery of drugs having poor polymer diffusion characteristics. Core-type rings contain the $\operatorname{drug}(\mathrm{s})$ within one or more central cores that are encapsulated by a drug-free outer polymer membrane (Figure $1 \mathrm{C}-\mathrm{E}$ ). Several individual drug-loaded cores of various lengths may be incorporated into the same core ring, thereby allowing delivery of multiple actives at predetermined and independent release rates. The release rates of both the core and sandwich-ring designs may be further modified by changing the thickness of the rate-controlling outer membrane.

The range of materials used in the manufacture of vaginal rings is limited by the requirements for biocompatibility, flexibility, and high drug permeability. Commercial ring products are made from either silicone (polydimethylsiloxane) elastomer or PEVA. More recently, thermoplastic polyurethane materials have also being investigated for ring fabrication. ${ }^{6-9}$ 


\section{Silicone elastomer vaginal rings}

Silicones represent a category of synthetic polymers comprising a main chain of alternating silicon and oxygen atoms, and having two organic groups covalently bonded to the silicon atom (Figure 2).${ }^{10}$ The most common silicone derivative is that having two methyl groups, called polydimethylsiloxane. The linear polymeric forms of silicones are liquids at room temperature, even for large molecular weights. Elastomeric silicone materials are produced by incorporating reactive functional groups into the linear polymers that may be subsequently "cross-linked" using suitable cross-linking molecules. Silicone polymers, and particularly the elastomeric forms, have a long history of use in both medical devices and drug-delivery devices, stemming from their excellent biocompatibility and biodurability. ${ }^{11}$ Silicone elastomer rings are generally made by elevated-temperature reaction injection molding, using either condensation or addition-cure chemistries. ${ }^{10}$

Two estrogen-releasing, reservoir-type silicone elastomer vaginal rings have been commercialized for the treatment of menopausal symptoms related to estrogen deficiency. Estring $^{\circledR}$ (Pfizer, New York, NY) contains a full-length reservoir core (Figure 1C) and releases $7.5 \mu \mathrm{g}$ /day of $17 \beta$-estradiol continuously over 3 months for the treatment of local symptoms. Femring ${ }^{\circledR}$ (Warner Chilcott UK Ltd, Larne, Northern Ireland) contains a single partial-length reservoir core (single-core version of Figure 1D) and releases either $50 \mu \mathrm{g} /$ day or $100 \mu \mathrm{g} /$ day (depending on core length) of the estradiol prodrug $17 \beta$-estradiol-3-acetate over 3 months for the treatment of both systemic and local symptoms. Both rings show a high degree of user acceptability and are preferred by women over estrogen vaginal gels. ${ }^{12-15}$ A 1-year combination contraceptive ring device, worn for 3 weeks per cycle and simultaneously releasing $15 \mathrm{mcg} /$ day ethinyl estradiol and $150 \mathrm{mcg} /$ day nestorone, is also in clinical development. ${ }^{16-19}$

The first report of a microbicide-releasing vaginal ring described the continuous in vitro release over 8 days of the non-ionic surfactant nonoxynol-9 from a matrix-type silicone elastomer device. ${ }^{20}$ Unlike the solid antiretroviral compounds currently being tested as HIV microbicides, nonoxynol-9 is a liquid at a room temperature, such that its release from the ring followed unconventional release kinetics. Nonoxynol-9 has since been discontinued as a microbicide candidate since studies showed that it increased the risk of HIV transmission following frequent application. ${ }^{21,22} \mathrm{~A}$ subsequent study showed that dapivirine (also known as TMC120) could be effectively released in vitro over 71 days from a silicone elastomer reservoir-type ring device..$^{23}$ Moreover, it was calculated that the constant daily rate observed of $130 \mu \mathrm{g}$ release could effectively be maintained for at least 1 year, and theoretically for up to 4 years.

Many of the lead-candidate antiretroviral compounds being developed as HIV microbicides (eg, dapivirine, maraviroc, UC781, and MC1220) have physicochemical properties (specifically, high hydropobicity and low molecular weight) very similar to those of steroid molecules, suggesting that silicone elastomer vaginal ring formulations may also be
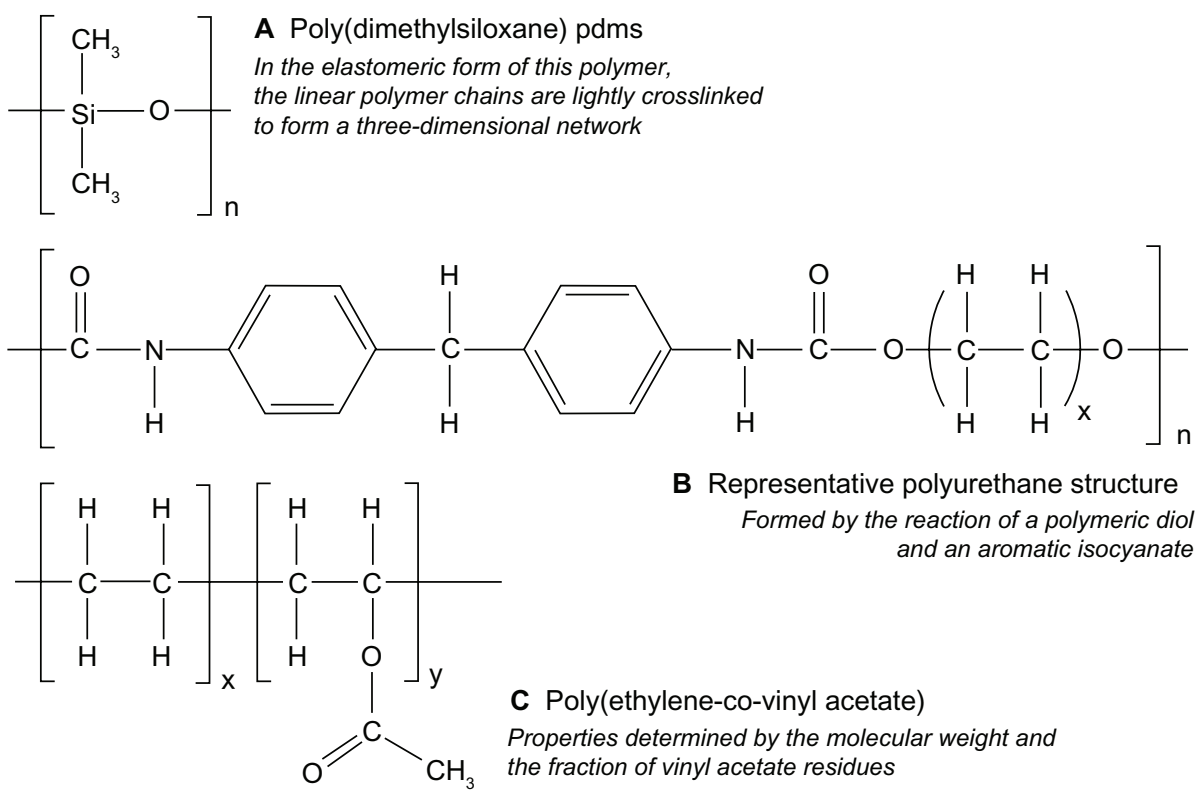

B Representative polyurethane structure Formed by the reaction of a polymeric diol and an aromatic isocyanate

Figure 2 Chemical structures representing (A) silicone, (B) polyurethane and (C) poly(ethylene-co-vinyl acetate) materials used in the fabrication of drug-releasing vaginal rings. 
useful for the controlled release of microbicides. Although numerous antiretroviral compounds have been tested in rings in vitro, only the dapivirine-matrix and reservoir-type silicone elastomer rings have reached the clinical stages of development (Table 1). Two Phase I safety studies have been completed for a $200 \mathrm{mg}$ dapivirine reservoir ring (study IPM 001) (Figure 3A), ${ }^{24}$ a $25 \mathrm{mg}$ dapivirine reservoir ring (studies IPM 008 and IPM 01) (Figure 3B), ${ }^{24,25}$ and a $25 \mathrm{mg}$ dapivirine matrix ring (study IPM 018) (Figure 3C). ${ }^{21}$ Although these rings had different designs, they were both manufactured using a condensation-cure silicone elastomer system specifically designed for the incorporation and release of drug molecules. The IPM 001 and IPM 008 studies demonstrated good safety and tolerability for both the $25 \mathrm{mg}$ and $200 \mathrm{mg}$ dapivirine reservoir-type rings, compared with a placebo ring, during the 7-day study period. Reported vaginal-fluid concentrations of dapivirine at various locations along the cervicovaginal tract (introitus, cervix, ring position) were in the range $0.7-7.1 \mu \mathrm{g} / \mathrm{mL}$, with levels highest close to the ring and lowest at the introitus. Vaginal- and cervical-tissue concentrations on day 7 were between $0.3 \mu \mathrm{g} / \mathrm{g}$ and $3.5 \mu \mathrm{g} / \mathrm{g}$. Plasma concentrations, which are a particularly important consideration from the perspective of the potential emergence of strains resistant to the drug in HIV-positive users, were less than $50 \mathrm{pg} / \mathrm{mL}$. Dapivirine concentrations in vaginal fluid and tissue were more than three orders of magnitude greater than the in vitro EC50 against a wild-type HIV-1 strain. ${ }^{26,27}$ Dapivirine levels measured with the $25 \mathrm{mg}$ continuous core device (Figure 3B) were generally higher (but did not reach statistical significance) than those for the $200 \mathrm{mg}$ two-core ring device (Figure 3A). This is consistent with the nature of membrane-type diffusion-controlled drug-delivery systems, where drug release kinetics are determined by the length of the reservoir and the thickness of the rate-controlling membrane, but not the drug-loading (which only influences the duration of release). ${ }^{28}$

Reservoir rings are associated with several disadvantages compared with matrix-type rings, most notably their complexity of manufacture (a multistep process) and the relatively low (but constant) release rates. In the IPM 018 study (Table 1), the pharmacokinetics of matrix and reservoir rings, each containing $25 \mathrm{mg}$ dapivirine (Figure 3B and C), were compared. ${ }^{25}$ The results clearly illustrated differences in dapivirine release rates, with significantly higher plasma
A IPM 001, Romano et al24

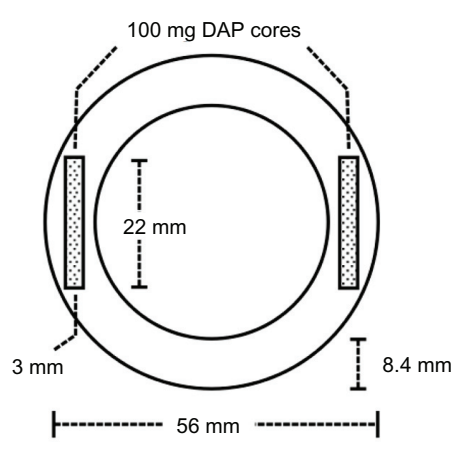

C IPM 013, IPM 018, IPM 024, IPM 027 , MTN 020, Malcolm et al ${ }^{23}$, Nel et $a^{25}$

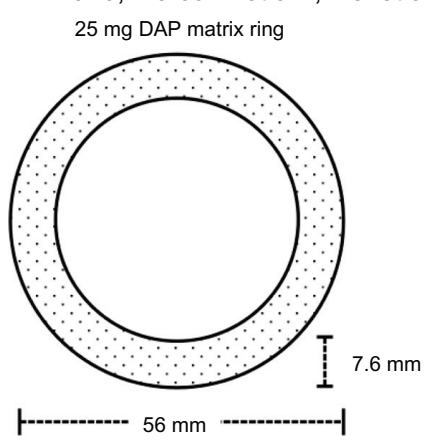

B IPM 008, IPM 018, Romano et $\mathrm{al}^{24}$, Nel et $\mathrm{al}^{25}$

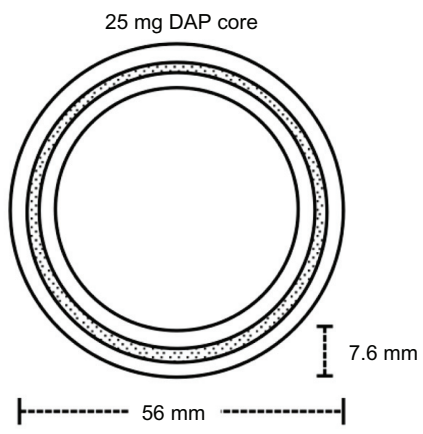

D Malcolm et $\mathrm{al}^{23}$

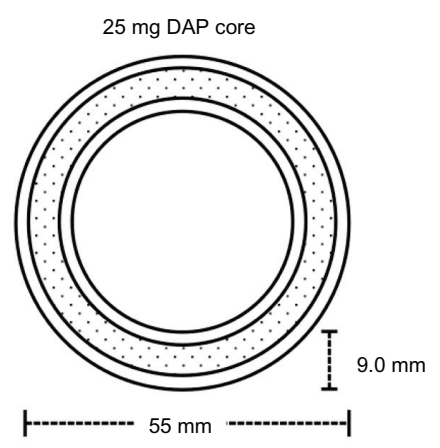

Figure 3 Schematic diagrams (to scale) describing the design and dimensions of dapivirine-releasing vaginal rings. The design in (A) was evaluated in clinical study IPM $00 \mathrm{I}$ (Table I) and reported in Romano et al. ${ }^{24}$ The design in (B) was evaluated in IPM 008 and IPM 018 (Table I), and reported in Romano et al ${ }^{24}$ and Nel et al. ${ }^{25}$ The design in (C) is the $25 \mathrm{mg}$ dapivirine matrix ring due to progress to Phase III in 2012 as part of study MTN 020 (Table I). It was previously tested in IPM 013 , IPM 018 , IPM 024, and IPM 027 (Table I), and has been reported in Nel et al..$^{25}$ The design in (D) is the reservoir-type dapivirine-releasing ring first reported in the literature by Malcolm et al. ${ }^{23}$ 
Table I Completed, ongoing and planned microbicide ring clinical studies

\begin{tabular}{|c|c|c|c|c|c|}
\hline Study & Description & Phase & Countries & Number women & Status \\
\hline IPM 00I & Dapivirine ring safety & I & Belgium & 12 & Completed \\
\hline IPM 008 & Dapivirine ring safety & I & Belgium & 13 & Completed \\
\hline IPM 0II & Placebo ring safety and acceptability & $\mathrm{n} / \mathrm{a}$ & South Africa/Tanzania & 170 & Completed \\
\hline IPM 013 & Dapivirine ring PK & 1 & Belgium & 48 & Completed \\
\hline IPM 015 & Dapivirine ring safety & $\mathrm{I} / \mathrm{II}$ & Kenya, Malawi, South Africa, Tanzania & 280 & Data analysis \\
\hline IPM 018 & Dapivirine ring PK & I & Belgium & 24 & Completed \\
\hline IPM 024 & Dapivirine ring PK & 1 & Belgium & 16 & Completed \\
\hline IPM 026/ & Maraviroc, dapivirine, and & I & USA & 48 & Ongoing in 2012 \\
\hline MTN 013 & dapivirine-maraviroc combination ring & & & & \\
\hline IPM 027 & Dapivirine ring long-term safety & II & South Africa, Rwanda, Kenya, Malawi & 1650 & Ongoing in 2012 \\
\hline MTN 020 & Dapivirine ring efficacy and safety & III & $\begin{array}{l}\text { Malawi, South Africa, Uganda, } \\
\text { Zambia, Zimbabwe }\end{array}$ & 3475 & Ongoing in 2012 \\
\hline
\end{tabular}

Notes: IPM refers to clinical studies completed or being undertaken by the International Partnership for Microbicides (Silver Spring, MD). MTN refers to studies being undertaken by the Microbicide Trails Network, a US National Institutes of Health-funded worldwide collaborative clinical trials network focused on preventing the sexual transmission of HIV.

Abbreviations: MRI, magnetic resonance imaging; PII, Phase II; C, control.

and vaginal-fluid levels achieved with the matrix format, owing to the presence and rapid release of the drug at the device surface (Figure 4). Vaginal-fluid levels peaked at $\sim 1000 \mu \mathrm{g} / \mathrm{g} 24$ hours after placement of the matrix ring, and declined steadily to around $\sim 10 \mu \mathrm{g} / \mathrm{g}$ on day 28 , immediately prior to ring removal (Figure 4D). In general, vaginalfluid levels for the reservoir ring were between one and two orders of magnitude lower than those for the matrix ring.
A

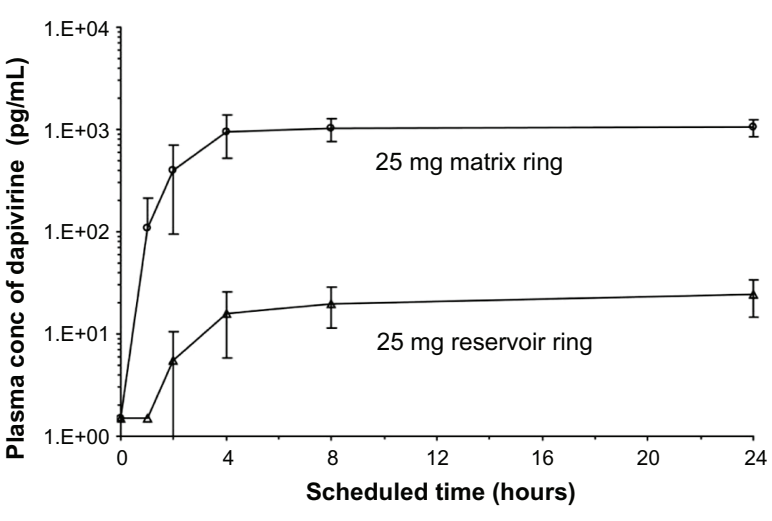

B

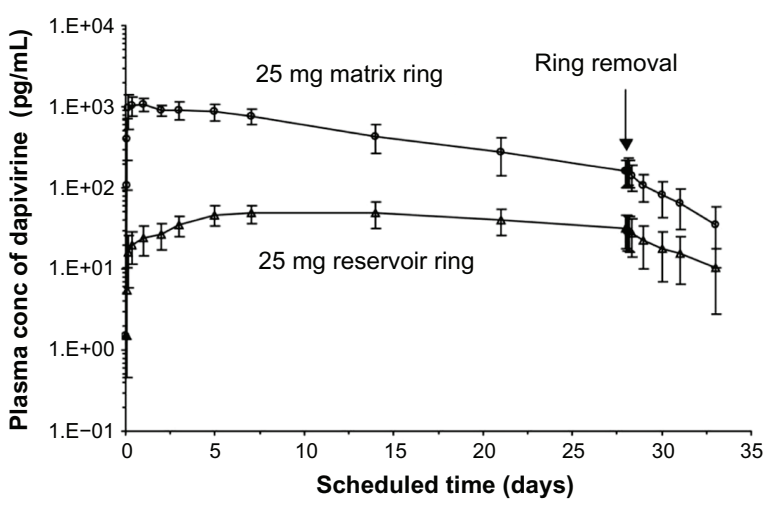

C

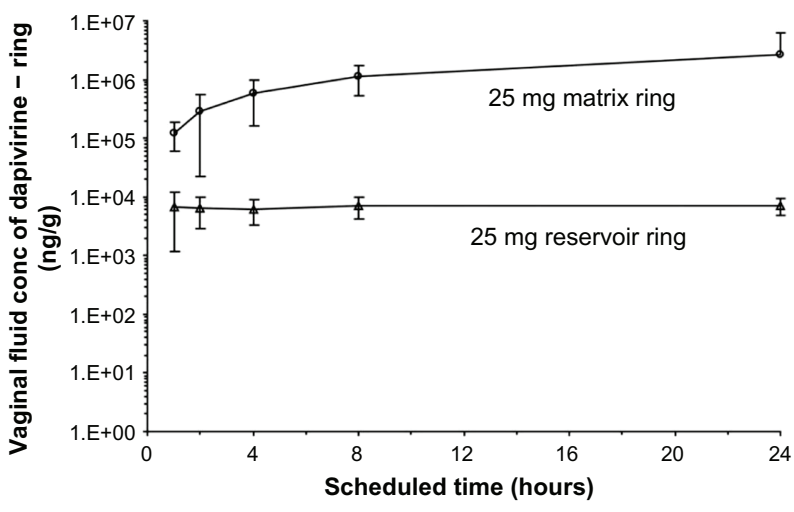

D

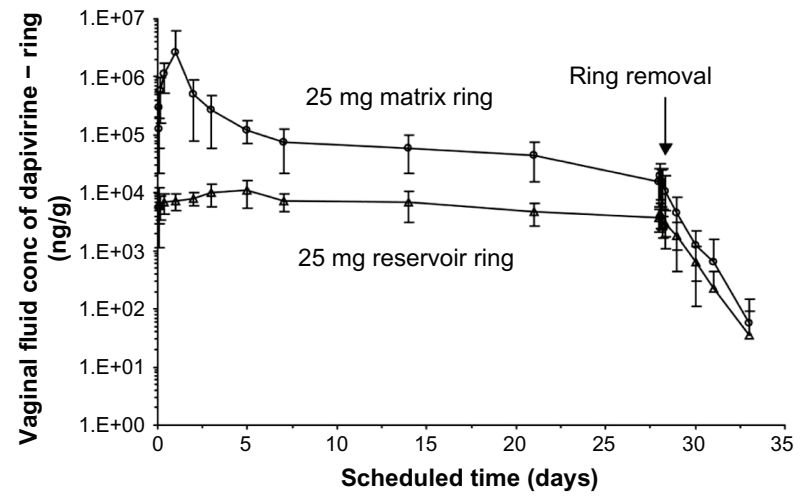

Figure 4 Reported pharmacokinetic profiles for the $25 \mathrm{mg}$ matrix and $25 \mathrm{mg}$ reservoir rings tested in IPM 018 . (A and B) show plasma concentrations (conc) over 24 hours and 33 days, respectively. (C and $\mathbf{D})$ show vaginal-fluid concentrations over 24 hours and 33 days, respectively.

Note: Rings were inserted at $\mathrm{t}=0$ and removed on day 28.

(C) 2009 Lippincott Williams and Wilkins. Reprinted with permission. Nel A, Smythe S, Young K, et al. Safety and pharmacokinetics of dapivirine delivery from matrix and reservoir intravaginal rings to HIV-negative women. ${ }^{25}$ 
Plasma levels of dapivirine ranged from $10-1000 \mathrm{pg} / \mathrm{mL}$ (Figure 4A and B).

The propanol by-product associated with condensationtype silicone elastomers can lead to a "drug burst effect," where the incorporated solid drug is dissolved in the propanol, transported to the device surface, and subsequently deposited following evaporation of the propanol. ${ }^{29-31}$ This solvent-aided deposition of the drug can artificially increase its release rate during the early period of use, beyond that attributed to the normal polymer diffusion-controlled process. Subsequent studies have confirmed that a substantial drug burst occurred with the early prototype condensation-cure dapivirine-releasing silicone elastomer rings, prompting a move to addition-cure silicone elastomer systems (which produce no solvent by-product during the silicone-curing reaction) for the future clinical development of the dapivirine matrix ring. Preliminary pharmacokinetic data (unpublished) from the IPM013 and IPM024 Phase 1 studies for the addition-cure $25 \mathrm{mg}$-dapivirine ring showed detection of dapivirine in both vaginal fluid and plasma 1.5 hours after ring insertion; the maintenance of dapivirine concentrations in vaginal fluid was in the $10-50 \mathrm{mcg} / \mathrm{g}$ range over the 35-day study period. The ASPIRE Phase III study (MTN 020, Table 1) of the addition-cure silicone elastomer $25 \mathrm{mg}$ dapivirine ring will be launched at several African sites in 2012 and involve almost 3500 women. First results are anticipated in late 2014 or early 2015.

Following the success of antiretroviral combinations for the treatment of HIV infection, there is also considerable interest in combination microbicide products, including vaginal rings, that simultaneously release two or more microbicide compounds having different mechanisms of action. The first clinical trial of such a ring (IPM 026/MTN 013, Table 1), comprising $25 \mathrm{mg}$ dapivirine and $100 \mathrm{~g}$ maraviroc (an entry inhibitor) in an addition-cure silicone elastomer matrix format (Figure 1B) is planned for 2012 with 48 healthy women using either the combination ring, a $25 \mathrm{mg}$ dapivirineonly ring, a $100 \mathrm{mg}$ maraviroc-only ring, or a placebo ring continuously for 28 days.

Microbicide-releasing silicone elastomer vaginal rings have also been designed for use in macaques, enabling important pharmacokinetic and challenge studies to be performed in a more clinically relevant nonhuman-primate model. ${ }^{32-34}$

\section{Thermoplastic vaginal rings}

Thermoplastics are polymer substances that melt (and flow) upon heating and that harden again upon subsequent cooling. While most thermoplastic materials are not suitable for the fabrication of vaginal rings owing to their poor flexural and mechanical characteristics, a subset known as "thermoplastic elastomers" has been successfully applied to vaginal ring construction. Most notably, ethylene vinyl acetate copolymers (PEVA) are used as both the drug matrix and the rate-limiting sheath in the combination (etonogestrel + ethinyl estradiol) contraceptive vaginal ring device Nuvaring ${ }^{\circledR}$. A number of other subdermal, implantable drug-delivery devices are also fabricated from PEVA, including Implanon ${ }^{\circledR}$ and Virtasert ${ }^{\circledR}$. The vinyl acetate content (typically ranging from approximately $10 \%$ to $40 \%$ ) and the molecular weight characteristics of the PEVA material play a major role in determining the mechanical properties, the ease of processing, and the drug release rates of the finished drug-delivery device.

Nuvaring ${ }^{\circledR}$ is a nonbiodegradable, flexible, transparent, colorless, contraceptive vaginal ring (Table 1), developed by Organon Inc and first marketed in 2002. It contains two active compounds, progestin etonogestrel $(11.7 \mathrm{mg})$ and estrogen ethinyl estradiol $(2.7 \mathrm{mg})$, both located within a central PEVA ( $28 \% \mathrm{w} / \mathrm{w}$ vinyl acetate) core as a supersaturated eutectic mixture, and surrounded by a nonmedicated polyethylene-co-vinyl acetate ( $9 \% \mathrm{w} / \mathrm{w}$ vinyl acetate) sheath layer. The slow permeation of the steroid molecules through the low-vinyl-acetate-content nonmedicated sheath provides for controlled release, resulting in mean daily release rates of $120 \mu \mathrm{g}$ etonogestrel and $15 \mu \mathrm{g}$ ethinyl estradiol over the 3 -week period of use. The ring is used continuously for 3 weeks, and then removed for 1 week before being replaced with a new ring. Nuvaring ${ }^{\circledR}$ is highly efficacious, with a Pearl index of 1.18 and an efficacy of $99.1 \%$. Off-label 28-day continuous use of Nuvaring ${ }^{\circledR}$ is also being evaluated. ${ }^{35}$

Despite the commercial success of Nuvaring ${ }^{\circledR}$, there have been very few reports of the use of PEVA for microbicidereleasing vaginal rings, probably owing to ongoing difficulties in accessing clinical-grade materials for testing in humans. A comparison of the pharmacokinetics of the nonnucleoside reverse-transcriptase inhibitor UC781 in rabbits following vaginal administration of ring segments fabricated from PEVA, polyurethane, and silicone elastomer showed similar in vivo release rates and kinetics. ${ }^{8}$ Recently, a combination PEVA matrix-type ring providing simultaneous release of the microbicide candidate UC781 and the contraceptive progestin levonorgestrel has been reported. ${ }^{36}$ If the proof of concept of a microbicide vaginal ring device can be realized with the dapivirine-releasing silicone elastomer ring, then these multipurpose prevention technologies that combine HIV protection with effective contraceptive regimes will be actively pursued. 
Table 2 Summary of microbicide-releasing vaginal ring devices either previously evaluated or under ongoing investigation

\begin{tabular}{|c|c|c|c|}
\hline Microbicide(s) & Polymer type & Ring type & References \\
\hline \multirow[t]{3}{*}{ Dapivirine } & Silicone elastomer & Reservoir and matrix & $23,24,25$ \\
\hline & Polyurethane & Matrix & $6,7,9$ \\
\hline & Biosoluble acacia gum & Reservoir & 45 \\
\hline Maraviroc & Silicone elastomer & Matrix & 34 \\
\hline CMPDI67 & Silicone elastomer & Matrix & 34 \\
\hline $\mathrm{MCI} 220$ & Silicone elastomer & Matrix & 33 \\
\hline $\mathrm{AZT}$ & Biosoluble acacia gum or a hydrogel & Reservoir & 44,45 \\
\hline Boc-LBA & Biosoluble acacia gum & Reservoir & 45 \\
\hline \multirow[t]{2}{*}{ Tenofovir } & Silicone elastomer (carrier) & Pod ring & 38,40 \\
\hline & Polyurethane & Matrix & \\
\hline MIV-I60 & Poly(ethylene-co-vinyl acetate) & Matrix & 58 \\
\hline \multirow[t]{3}{*}{ UC78I } & Silicone elastomer & Matrix & 8 \\
\hline & Polyurethane & Matrix & 8,37 \\
\hline & Poly(ethylene-co-vinyl acetate) & Matrix & 36 \\
\hline \multirow[t]{2}{*}{ Dapivirine + tenofovir } & Biosoluble acacia gum or a hydrogel & Reservoir & 45 \\
\hline & Polyurethane & Matrix & 7 \\
\hline \multirow[t]{2}{*}{ Dapivirine + maraviroc } & Silicone elastomer & Matrix & $\mathrm{n} / \mathrm{a}$ \\
\hline & Poly(ethylene-co-vinyl acetate) & Matrix & $\mathrm{n} / \mathrm{a}$ \\
\hline Tenofovir and acyclovir & Silicone elastomer (carrier) & Pod ring & 38 \\
\hline IQP-0528 and tenofovir & Polyurethane & Matrix & $\mathrm{n} / \mathrm{a}$ \\
\hline Saquinavir, lopinavir and ritonavir & Silicone elastomer & Matrix & $\mathrm{n} / \mathrm{a}$ \\
\hline
\end{tabular}

Abbreviations: n/a, reference not available; MRI, magnetic resonance imaging; PII, Phase II; C, control.

Thermoplastic polyurethanes are also being evaluated for use in microbicide-releasing vaginal rings. As with PEVA, the properties of polyurethanes can be readily tailored by controlling their chemical structure (Figure 2B), simply by adjusting the components of the reaction mixture (polymeric diol, a chain extender, and isocyanate) used in their synthesis. To date, polyurethane rings releasing either UC781, dapivirine, tenofovir, or a combination have been demonstrated in in vitro studies. ${ }^{6,7,9,37}$ Constant daily release of dapivirine from matrix-type ring prototypes was sustained over 30 days, with the release rate dependent on the initial drug-loading. ${ }^{6}$ Novel segmented polyurethane vaginal rings have also been evaluated for simultaneous release of dapivirine and tenofovir. Each drug was incorporated into its own rod segment before joining the rods to prepare the intact ring device. ${ }^{7}$ While this approach permits independent formulation of the component microbicides and control of release rates, the complexity of design and the required scaled manufacturing are obstacles to further development.

\section{New designs of vaginal ring for microbicide delivery}

Several new designs of vaginal ring device are also in development, all seeking to overcome the drug-permeability constraints associated with release of hydrophilic and/or macromolecular actives from conventional silicone elastomer and thermoplastic systems.
The Versaring ${ }^{\circledR}$ technology platform (Auritec Pharmaceuticals) is based on drug-loaded pod inserts, comprising polymer-coated solid drug, incorporated into a silicone elastomer ring and exhibiting pseudo-zero order release kinetics. ${ }^{38-40}$ Drug cores are coated with layers of semipermeable poly(lactic acid) polymer. Coated drug pods are incorporated into silicone rings, and the drug is released through a delivery window in the silicone ring, with the release rate determined by the window diameter. The amount of drug released from each ring can be adjusted by changing the amount and composition of the polymer coating of the drug core, the size of the drug-delivery window, and the number of drug pods in each ring. Vaginal rings containing tenofovir provide in vitro daily release rates spanning 2.5 orders of magnitude (10-4000 mcg/day for tenofovir). The modular nature of the rings permits the release of multiple drugs having very different physicochemical characteristics. To date, in vitro release of tenofovir and acyclovir from the same ring segments has been demonstrated..$^{40}$ In vivo studies have demonstrated sustained release of tenofovir in the micro-molar range over 14 days in rabbits and 28 days in macaques, with no local inflammation or altered vaginal flora. ${ }^{40}$ In rabbits, the vaginal tissue tenofovir levels at sacrifice were $3597 \pm 1678 \mathrm{ng} / \mathrm{g}$. In the macaques, vaginal biopsies proximal and distal to the inserted rings at days 7 and 21 measured tenofovir levels at $76 \pm 54 \mathrm{mcg} / \mathrm{g}$, over 100 times the IC 50 of tenofovir $(2 \mu \mathrm{M})$. The data demonstrates 
the feasibility of a 1-month tenofovir microbicide ring for women.

Similar to the pod-insert vaginal ring, rod and tablet-insert vaginal rings comprise one or more polymeric solid dosage forms (lyophilized polymer gel rods and directly compressed tablets, respectively) inserted into a silicone elastomer ring. ${ }^{41}$ While the ring acts primarily as a retainer for the solid dosage inserts, it may also be used to load and deliver other microbicide candidates compatible with conventional permeationcontrolled release mechanisms. Lyophilized inserts may be prepared by freeze-drying microbicide-loaded aqueous gel formulations. This technology is potentially useful for the production of solid dosage inserts containing peptide- and protein-based microbicide candidates, since it does not involve high temperatures, and the water-free insert serves to stabilize the active biomolecule. Once administered, the gel is slowly reconstituted by imbibing vaginal fluid, leading to sustained release of the active agent. Similar lyophilized tablets have recently been reported for the formulation of dapivirine. ${ }^{42}$ The compressed tablet-insert strategy makes use of traditional direct-compression tableting technology to manufacture conventional sustained-release solid dosage forms.
Given the regulatory constraints, very few polymer materials apart from silicone elastomer and PEVA have been considered, to date, for the fabrication of vaginal rings. Matrix-type rings constructed from styrene-butadiene block copolymers have previously been evaluated for the sustained release of $17 \beta$-estradiol for the treatment of postmenopausal symptoms. ${ }^{43}$ The use of polymers that control drug release by mechanisms other than permeation might be useful for the delivery of hydrophilic and/or large molecular weight actives. Vaginal rings constructed from biosoluble acacia gum, a nonbiodegradable hydrogel of 2-hydroxyethyl methacrylate, and sodium methacrylate, designed to provide sustained release for up to 28 days, have been reported for the simultaneous release of combination antiretroviral HIV microbicides and for combinations of microbicides with nonhormonal contraceptives. ${ }^{44,45}$

\section{A microbicide-releasing diaphragm}

The SILCS diaphragm has been under development by the Program for Appropriate Technology in Health since 1994 as an advanced, single-sized, cervical-barrier contraceptive device (Figure 5). ${ }^{46-51}$ Similar in format to a reservoir-type

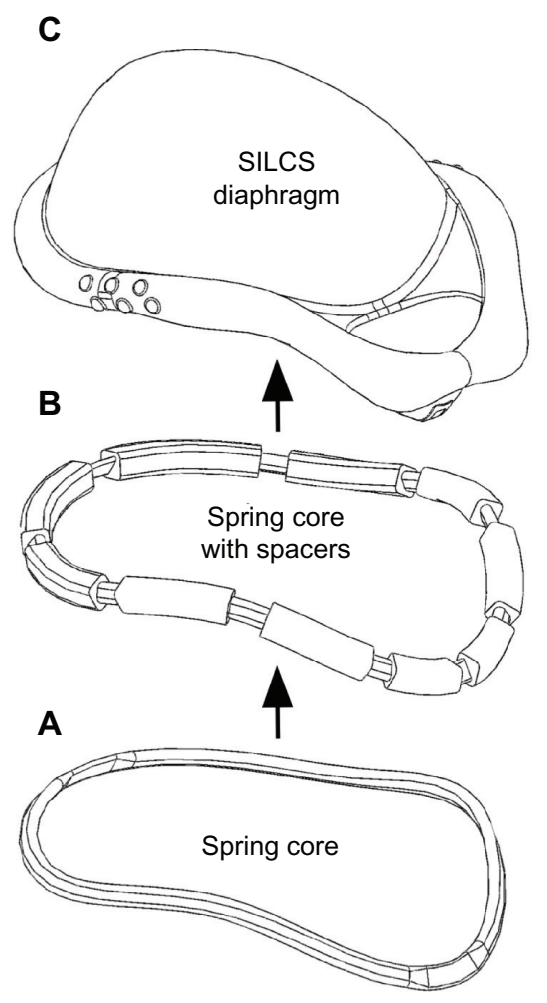

D
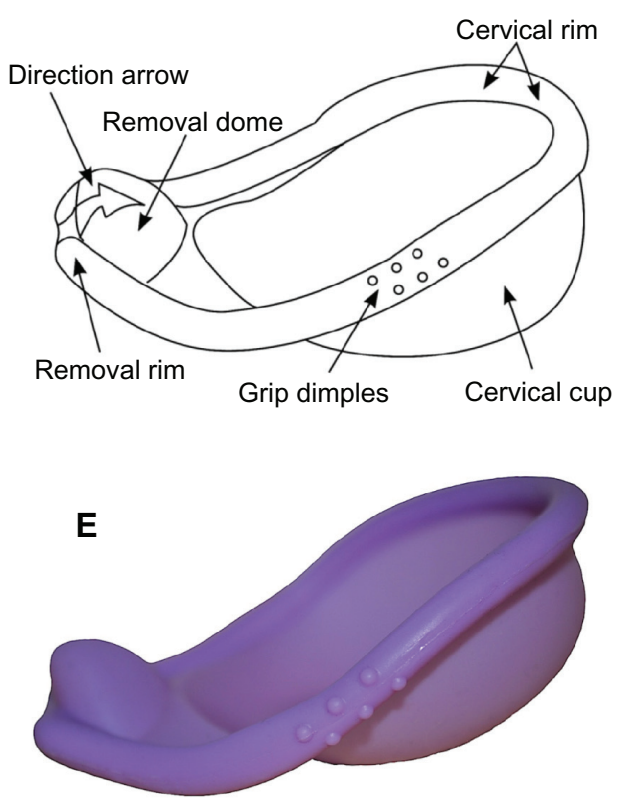

Figure 5 The SILCS diaphragm. (A) The thermoplastic spring core consists of nylon-6 in the original SILCS device and polyoxymethylene in the dapivirine-releasing device. (B) Spring core with over-molded silicone elastomer spacers, for positioning the spring core within the injection molds during the final overmolding step. (C) Finished diaphragm device, formed by overmolding the spring core + spacers with silicone elastomer. (D) Design features of the SILCS diaphragm. (E) Photograph of the SILCS diaphragm. 
vaginal ring device, SILCS contains a specially designed flexible polymeric spring core (made from nylon-6), which is over-molded with silicone elastomer to form the barrier sheath. In preliminary clinical studies, SILCS was found to be safe; and it performed as well as the standard latex diaphragm in preventing sperm from reaching the cervix when both devices were used with the spermicide nonoxynol-9. The contraceptive efficacy of SILCS is currently being evaluated in combination use with the contraceptive gel BufferGel ${ }^{\circledR}$. If protection is similar to the standard diaphragm, these data will provide the basis for an application to the US Food and Drug Administration.

Given the similarity of structure between the nonmedicated SILCS device and a reservoir-type, drug-releasing vaginal ring (ie, both contain a central polymeric core and an over-molded polymer sheath), and the newly emerging emphasis on the development of multipurpose prevention strategies, ${ }^{52-54}$ the incorporation of a microbicide delivery function into SILCS is currently being actively pursued..$^{55}$ A modified SILCS device comprising an injection-molded polyoxymethylene spring core, loaded with up to $20 \%$ dapivirine and over-molded with the standard silicone elastomer material, has been shown to provide constant in vitro daily release rates during continuous testing over 6 months. ${ }^{56}$

\section{Manufacturing and scale-up}

The general methods for the manufacture of silicone elastomer and thermoplastic vaginal rings, outlined in Figures 6 and 7 respectively, involve the incorporation of the solid drug active(s) into the polymer, followed by injectionmolding or extrusion into precision-machined ring-holds to

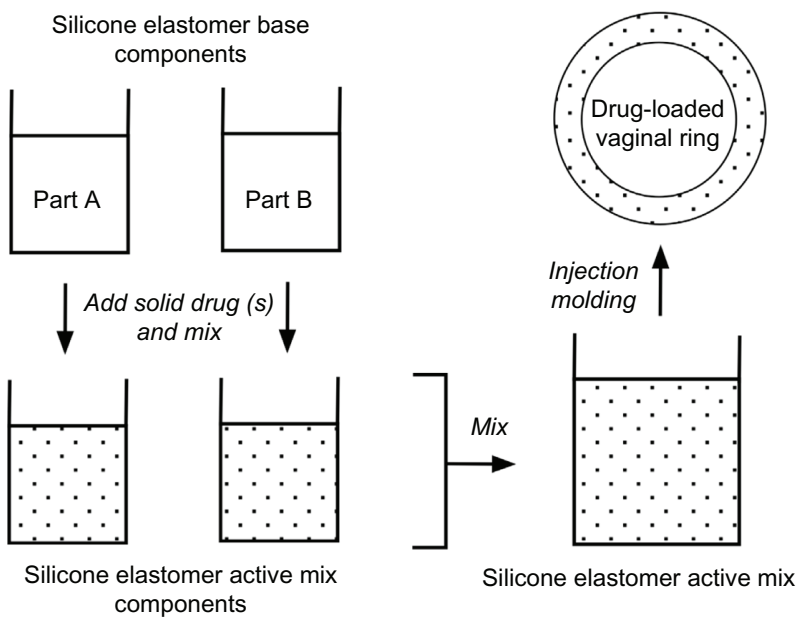

Figure 6 General manufacturing method for fabricating drug-loaded silicone elastomer matrix rings. More complex methods are required for advanced ring designs.

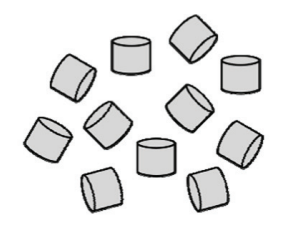

Thermoplastic pellets (as supplied)

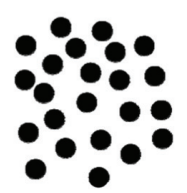

Solid drug substance (may be micronised)

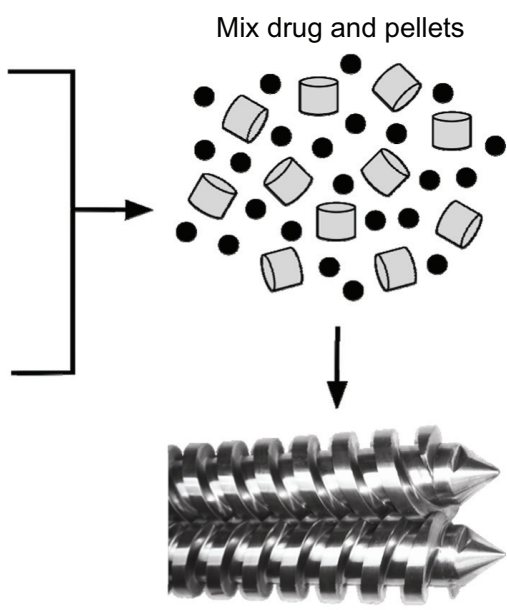

Mix and extrude in a

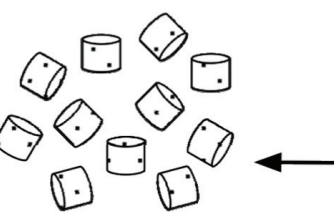

twin screw extruder

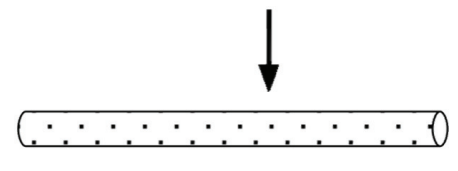

Drug-loaded thermoplastic pellets

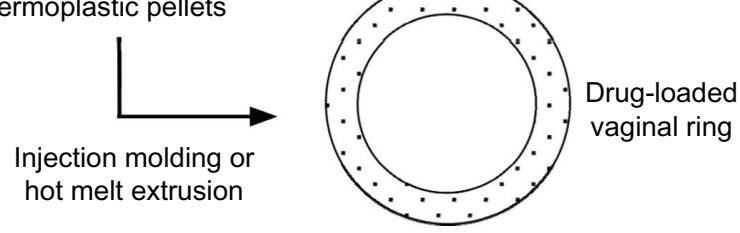

Figure 7 General manufacturing method for the fabrication of drug-loaded thermoplastic matrix rings. More complex methods are required for advanced ring designs.

form the final device. Depending on the format and complexity of the ring product design, there may be several distinct steps in the manufacturing process. Although the polymerprocessing techniques of injection molding and extrusion are ubiquitous in the manufacturing of plastic parts for a wide variety of everyday applications (including various medical devices), the availability of contract manufacturers capable of handling the regulatory issues, manufacturing complexities, and raw material supplies associated with drug-delivery devices is very limited. These issues have been discussed previously, ${ }^{57}$ and are particularly pertinent, given the progress of the $25 \mathrm{mg}$ dapivirine ring to Phase III clinical testing. If the MTN 020 trial (Table 1) successfully demonstrates the efficacy of the $25 \mathrm{mg}$ dapivirine matrix ring in reducing the incidence of HIV transmission, then several hurdles will need to be overcome before commercial launch, including accurate projected forecast demand and significant expansion of manufacturing capacity to meet global needs. 


\section{Disclosure}

The authors report no conflicts of interest in this work.

\section{References}

1. Folkman J, Long DM Jr, Rosenbaum R. Silicone rubber: a new diffusion property useful for general anesthesia. Science. 1966;154(3745): $148-149$.

2. Folkman J, Long DM. The use of silicone rubber as a carrier for prolonged drug therapy. J Surg Res. 1964;4(3):139-142.

3. Dziuk PJ, Cook B. Passage of steroids through silicone rubber. Endocrinology. 1966;78(1):208-211.

4. Duncan GW, inventor; The Upjohn Company, assignee. Medicated devices and methods. United States patent US 3545439. December 8, 1970 .

5. Hoffman AS. The origins and evolution of "controlled" drug delivery systems. J Control Release. 2008;132(3):153-163.

6. Gupta KM, Pearce SM, Poursaid AE, et al. Polyurethane intravaginal ring for controlled delivery of dapivirine, a nonnucleoside reverse transcriptase inhibitor of HIV-1. J Pharm Sci. 2008;97(10):4228-4239.

7. Johnson T, Gupta K, Fabian J, Albright T, Kiser P. Segmented polyurethane intravaginal rings for the sustained combined delivery of antiretroviral agents dapivirine and tenofovir. Eur J Pharm Sci. 2010;39(4):203-212.

8. Clark MR, Kiser PF, Loxley A, McConville C, Malcolm RK, Friend DR. Pharmacokinetics of UC781-loaded intravaginal ring segments in rabbits: a comparison of polymer matrices. Drug Deliv Transl Res. 2011;1(3):238-246.

9. Kaur M, Gupta KM, Poursaid AE, et al. Engineering a degradable polyurethane intravaginal ring for sustained delivery of dapivirine. Drug Delivery Trans Res. 2011;1(3):223-237.

10. Colas A, Curtis J. Silicone biomaterials: history and chemistry. In: Biomaterials Science: An Introduction to Materials in Medicine. 2nd ed. Elsevier Academic Press; 2004:80-85.

11. Curtis J, Colas A. Medical applications of silicones. In: Ratner BD, Hoffman AS, Schoen FJ, Lemons JE, editors. Biomaterials Science: An Introduction to Materials in Medicine. 2nd ed. Elsevier Academic Press; 2004:698-707.

12. Al-Azzawi F, Buckler HM; for the United Kingdom Vaginal Ring Investigator Group. Comparison of a novel vaginal ring delivering estradiol acetate versus oral estradiol for relief of vasomotor menopausal symptoms. Climacteric. 2003;6(2):118-127.

13. Barentsen R, vandeWeijer PHM, Schram JHN. Continuous low dose estradiol released from a vaginal ring versus estriol vaginal cream for urogenital atrophy. Eur J Obstet Gynecol Reprod Biol. 1997;71(1):73-80.

14. Buckler H, Al-Azzawi F; for the UK VR Multicentre Trial Group. The effect of a novel vaginal ring delivering oestradiol acetate on climacteric symptoms in postmenopausal women. Brit J Obstet Gynecol. 2003;110(8):753-759.

15. Speroff L. Efficacy and tolerability of a novel estradiol vaginal ring for relief of menopausal symptoms. Obstet Gynecol. 2003;102(4): 823-834.

16. Croxatto HB, Brache V, Massai R, et al. Feasibility study of Nestoroneethinylestradiol vaginal contraceptive ring for emergency contraception. Contraception. 2006;73(1):46-52.

17. Kumar N, Koide SS, Tsong Y, Sundaram K. Nestorone: a progestin with a unique pharmacological profile. Steroids. 2000;65(10-11):629-636.

18. Fraser IS, Weisberg E, Brache V, et al. Serum Nestorone and ethinyl estradiol levels, and ovulation inhibition in women using three different dosage combinations of a Nestorone progestogen-ethinyl estradiol contraceptive vaginal ring on a bleeding-signaled regimen. Contraception. 2005;72(1):40-45.

19. Sivin I, Mishell DR Jr, Alvarez F, et al. Contraceptive vaginal rings releasing Nestorone and ethinylestradiol: a 1-year dose-finding trial. Contraception. 2005;71(2):122-129.
20. Malcolm K, Woolfson D, Russell J, Andrews C. In vitro release of nonoxynol-9 from silicone matrix intravaginal rings. J Control Release. 2003;91(3):355-364.

21. Van Damme L, Ramgee G, Alvary M, et al. Effectiveness of COL1492, a nonoxynol-9 vaginal gel, on HIV-1 transmission in female sex workers: a randomised controlled trial. Lancet. 2002;360(9338): 971-977.

22. Roddy RE, Zekeng L, Ryan K, et al. A controlled trial of nonoxynol 9 film to reduce male-to-female transmission of sexually transmitted diseases. N Engl J Med. 1998;339:504-510.

23. Malcolm RK, Woolfson AD, Toner CF, et al. Long-term, controlled release of the HIV microbicide TMC120 from silicone elastomer vaginal rings. J Antimicrob Chemother. 2005;56(5):954-956.

24. Romano J, Variano B, Coplan P, Van Roey J, Douville K, Rosenberg Z. Safety and availability of dapivirine (TMC120) delivered from an intravaginal ring. AIDS Res Hum Retroviruses. 2009;25(5):483-488.

25. Nel A, Smythe S, Young K, et al. Safety and pharmacokinetics of dapivirine delivery from matrix and reservoir intravaginal rings to HIVnegative women. J Acquir Immune Defic Syndr. 2009;51(4):416-423.

26. Di Fabio S, Van Roey J, Giannini G, et al. Inhibition of vaginal transmission of HIV-1 in hu-SCID mice by the non-nucleoside reverse transcriptase inhibitor TMC120 in a gel formulation. AIDS. 2003;17(11): 1597-1604.

27. Herrewege YV, Michiels J, Van Roey J, et al. In vitro evaluation of nonnucleoside reverse transcriptase inhibitors UC-781 and TMC120R147681 as human immunodeficiency virus microbicides. Antimicrob Agents Chemother. 2004;48(1):337-339.

28. Woolfson AD, Elliott GR, Gilligan CA, Passmore CM. Design of an intravaginal ring for the controlled delivery of 17 beta-estradiol as its 3-acetate ester. J Control Release. 1999;61(3):319-328.

29. Woolfson AD, Malcolm RK, Gallagher RJ. Design of a silicone reservoir intravaginal ring for the delivery of oxybutynin. J Control Release. 2003;91(3):465-476.

30. Woolfson AD, Malcolm RK, Gorman SP, Jones DS, Brown AF, McCullagh SD. Self-lubricating silicone elastomer biomaterials. J Mater Chem. 2003;13(10):2465-2470.

31. Malcolm RK, McCullagh SD, Woolfson AD, Gorman SP, Jones DS, Cuddy J. Controlled release of a model antibacterial drug from a novel self-lubricating silicone biomaterial. J Control Release. 2004;97(2): 313-320.

32. Promadej-Lanier N, Smith J, Srinivasan P, et al. Development and evaluation of a vaginal ring device for sustained delivery of HIV microbicides to non-human primates. J Med Primatol. 2009;38(4):263-271.

33. Fetherston S, Geer L, Veazey RS, et al. Partial protection against multiple RT-SHIV162P3 vaginal challenge of rhesus macaques by a silicone elastomer vaginal ring releasing the NNRTI MC1220. J Antimicrob Chemother. In press.

34. Malcolm RK, Veazey RS, Geer L, et al. Sustained release of the CCR5 inhibitors CMPD167 and maraviroc from vaginal rings in rhesus macaques. Antimicrob Agents Chemother. 2012;56(5):2252-2258.

35. Sulak PJ, Smith V, Coffee A, et al. Frequency and management of breakthrough bleeding with continuous use of the transvaginal contraceptive ring: a randomized controlled trial. Obstets Gynecol. 2008;112(3):563-571.

36. Loxley A, Mitchnick M, Okoh O, et al. Ethylene vinyl acetate intravaginal rings for the simultaneous delivery of the antiretroviral UC781 and contraceptive levonorgestrel. Drug Delivery Trans Res. 2011;1(3): 247-255.

37. Clark MR, Johnson TJ, McCabe RT, et al. A hot-melt extruded intravaginal ring for the sustained delivery of the antiretroviral microbicide UC781. J Pharm Sci. 2012;101(2):576-587.

38. Baum MM, Butkyavichene I, Gilman J, et al. An intravaginal ring for the simultaneous delivery of multiple drugs. J Pharm Sci. 2012;101(8): 2833-2843.

39. Keller MJ, Malone AM, Carpenter CA, et al. Safety and pharmacokinetics of aciclovir in women following release from a silicone elastomer vaginal ring. J Antimicrob Chemother. 2012;67(8):2005-2012. 
40. Moss JA, Malone AM, Smith TJ, et al. Simultaneous delivery of tenofovir and acyclovir via an intravaginal ring. Antimicrob Agents Chemother. 2012;56(2):875-882.

41. Morrow RJ, Woolfson AD, Donnelly L, et al. Sustained release of proteins from a modified vaginal ring device. Eur J Pharm Biopharm. 2011;77(1):3-10.

42. Woolfson AD, Umrethia ML, Kett VL, et al. Freeze-dried, mucoadhesive system for vaginal delivery of the HIV microbicide, dapivirine: optimisation by an artificial neural network. Int J Pharm. 2010;388: 136-143.

43. Vartiainen J, Wahlström T, Nilsson CG. Effects and acceptability of a new 17 beta-oestradiol-releasing vaginal ring in the treatment of postmenopausal complaints. Maturitas. 1993;17(2):129-137.

44. Han YA, Singh M, Saxena BB. Development of vaginal rings for sustained release of nonhormonal contraceptives and anti-HIV agents. Contraception. 2007;76(2):132-138.

45. Saxena B, Han Y, Fu D, et al. Sustained release of microbicides by newly engineered vaginal rings. AIDS. 2009;23(8):917-922.

46. Yang CC, Maravilla KR, Kilbourne-Brook M, Austin G. Magnetic resonance imaging of SILCS diaphragm: anatomical considerations and corroboration with clinical fit. Contraception. 2007;76(3):238-244.

47. Coffey PS, Kilbourne-Brook M, Brache V, Cochón L. Comparative acceptability of the SILCS and Ortho ALL-FLEX ${ }^{\circledR}$ diaphragms among couples in the Dominican Republic. Contraception. 2008;78(5): $418-423$

48. Coffey PS, Kilbourne-Brook M. Wear and care of the SILCS diaphragm: experience from three countries. Sex Health. 2010;7(2):159-164.

49. Coffey PS, Kilbourne-Brook M, Beksinska M, Thongkrajai E. Short-term acceptability of a single-size diaphragm among couples in South Africa and Thailand. J Fam Plann Reprod Health Care. 2008;34(4):233-236.
50. Schwartz JL, Ballagh SA, Creinin MD, et al. SILCS diaphragm: postcoital testing of a new single-size contraceptive device. Contraception. 2008;78(3):237-244.

51. Moench TR, Chipato T, Padian NS. Preventing disease by protecting the cervix: the unexplored promise of internal vaginal barrier devices. AIDS. 2001;15(13):1595-1602.

52. Friend D. Intravaginal rings: controlled release systems for contraception and prevention of transmission of sexually transmitted infections. Drug Deliv Transl Res. 2011;1(3):185-193.

53. Friend D, Doncel G. Combining prevention of HIV-1, other sexually transmitted infections and unintended pregnancies: development of dual-protection technologies. Antiviral Res. 2010;88 Suppl 1: S47-S54.

54. Thurman AR, Clark MR, Doncel GF. Multipurpose prevention technologies: biomedical tools to prevent HIV-1, HSV-2, and unintended pregnancies. Infect Dis Obstet Gynecol. Epub 2011 Aug 9.

55. Major I, Lowry D, Malcolm K, et al. Development of a microbicidereleasing diaphragm as an HIV prevention strategy. Conf Proc IEEE Eng Biol Soc. 2010:1089-1092.

56. Major I, Boyd P, Kilbourne-Brook M, et al. A modified SILCS contraceptive diaphragm for long-term controlled release of the HIV microbicide dapivirine. Contraception. In press.

57. Malcolm RK, Edwards KL, Kiser P, Romano J, Smith TJ. Advances in microbicide vaginal rings. Antiviral Res. 2010;88 Suppl 1: S30-S39.

58. Aravantinou M, Singer R, Derby N, et al. The nonnucleoside reverse transcription inhibitor MIV-160 delivered from an intravaginal ring, but not from a carrageenan gel, protects against simian/human immunodeficiency virus-RT infection. AIDS Res Human Retrovir. 2012 In press.
International Journal of Women's Health

\section{Publish your work in this journal}

The International Journal of Women's Health is an international, peerreviewed open-access journal publishing original research, reports, editorials, reviews and commentaries on all aspects of women's healthcare including gynecology, obstetrics, and breast cancer. The manuscript management system is completely online and includes

\section{Dovepress}

a very quick and fair peer-review system, which is all easy to use. Visit http://www.dovepress.com/testimonials.php to read real quotes from published authors. 